\title{
The Patient Experiences Hallucinations with Schizophrenia
}

\author{
Sri Eka Wahyuni*(D), Mahnum Lailan Nasution (D, Wardiyah Daulay (D) \\ Department of Psychiatric and Community Nursing, Nursing Faculty, Universitas Sumatera Utara, Medan, Indonesia
}

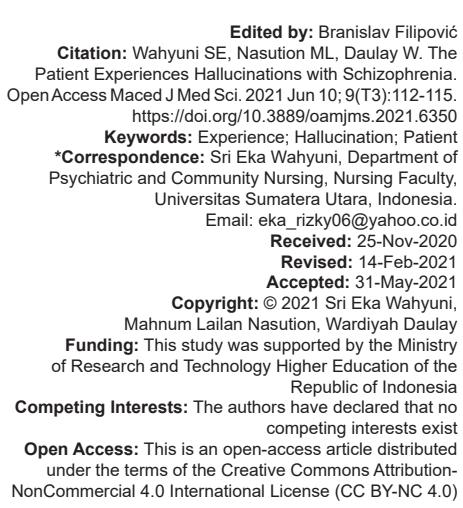

Edited by: Branislav Filipović Citation: Wahyuni SE, Nasution ML, Daulay W. The Patient Experiences Hallucinations with Schizophrenia. Open Access Maced J Med Sci. 2021 Jun 10; 9(T3): 112-115 https://doi.org/10.3889/oamjms.2021.6350 Keywords: Experience; Hallucination; Patient
${ }^{*}$ Correspondence: Sri Eka Wahyuni, Department of Psychiatric and Community Nursing, Nursing Faculty,
Universitas Sumatera Utara, Indonesia. Email: eka_rizky06@yahoo.co.id Received: 25-Nov-2020 Revised: 14-Feb-2021
Accepted: 31-May-2021 Copyright: @ 2021 Sri Eka Wahyuni, Copyright: @ 2021 Sri Eka Wahyun
Mahnum Lailan Nasution, Wardiyah Daulay Funding: This study was supported by the Ministry of Research and Technology Higher Education of the Competing Interests: The authors have declared that no Open Access: This is an open-access article distributed under the terms of the Creative Commons AttributionNonCommercial 4.0 International License (CC BY-NC 4.0)

\begin{abstract}
BACKGROUND: Hallucination is a psychosis symptom which mostly experienced by patients with schizophrenia It is also the experience of false perception undergone by patients without any stimulus from the environment. That experience of perception is real to the patients but not for others who do not have a similar perception of experience with the patients.

AIM: This research is phenomenological and aims for describing the experiences of patients with schizophrenia who had hallucination.

MATERIALS AND METHODS: This research took 15 patients. In this research, approaches and trust-building were accomplished before conducting a deep interview process. This research was conducted at Prof. Ildrem Asylum Medan. The data analysis was Colaizzi's method.

RESULTS: This research resulted in six themes, namely hallucination content, predisposition factor that causes hallucination, patients' subjective response when hallucinating, the distress facing by the patients with hallucination, actions taken when hallucinating, and the obstacles experienced by the patients.

CONCLUSIONS: This research provides a description to all medical officers to prioritize giving therapy to overcome patients' hallucination.
\end{abstract}

\section{Introduction}

Hallucination is a false sense experience which a patient has without any stimulation toward the receptor. Hallucination is a false sensory involving one of the five human senses, such as hearing, sight, smelling, groping, and tasting [1]. Perception experience had by patients is real to them but not for others.

Hallucination has become a major phenomenon on patients with schizophrenia. From many forms of hallucination, hearing hallucination is the dominant type encountered in patients with schizophrenia [2]. Hearing hallucination is a psychosis symptom which mostly happens [3]. Hallucination description happening on patients with schizophrenia is there are $20 \%$ patients experiencing two simultaneous hallucinations, namely hearing hallucination and sight hallucination, $70 \%$ patients with hearing hallucination, $20 \%$ patients experiencing sight hallucination, and $10 \%$ patients facing other hallucinations such as smelling, groping, and tasting hallucination [4]. This explains that hallucination is the prime problem on patients with schizophrenia and therefore, they should get fine treatment from health officers.

Hallucination should be the focus of attention of the health officers because if hallucination is not well-handled, the patients, others, and surroundings' safety will be in risk. This occurs because hallucination often contains with the command to hurt the patients themselves or even the people around them. The research result also showed that hallucination causes distress or nuisance to patient's life and daily activity [5]. The distress is due to frequent hallucination which happens every day and very loud voice until it disturbs the patient. The hallucination content is also scary, bothersome, and influential to the patient's belief [6]. Patients with hallucination also repeatedly feel fear, anxiousness, and depression caused by the hallucination. Amount $40 \%$ patients with schizophrenia experience depression caused by hearing hallucination [5]. Nine until $13 \%$ patients with schizophrenia commit suicide because of the hallucination containing command to hurt themselves [4]. The prevalence of the patients with schizophrenia committing suicide is $20-50 \%$. This is due to the hallucination had by them.

\section{Methods}

This research is phenomenological and aims for describing the experiences of patients with schizophrenia who had a hallucination. This research got 15 patients involved in it. Inclusion criteria of my study are patients with schizophrenia paranoid who had hallucination. In this research, approaches, and 
trust-building were accomplished before conducting deep interview process. This research was conducted at Prof. Ildrem Asylum Medan. This research has been through an ethical clearance from the ethics commission, Faculty of Nursing Universitas Sumatera Utara. All respondents were given an explanation of the aims and procedures of the study, and they stated their willingness to take part in the study by signing informed consent.

\section{Results}

Based on the data identification result of 15 patients with hallucination at Prof. Ildrem Asylum were recruited for this study. The majority of the patient's age was $18-40$ years $(45.5 \%)$, most of them are Muslim (57.6\%), male $(64.6 \%)$, and duration of treatment $<1$ year $(68.7 \%)$. Patient characteristics can be seen in Table 1:

Table 1: Characteristics of patients

\begin{tabular}{lll}
\hline Characteristics & $\mathrm{n}$ & $\%$ \\
\hline Ages & 3 & \\
$\quad<18$ years & 8 & 20.0 \\
$\quad 18-40$ years & 4 & 45.5 \\
$\quad>40$ years & & 25.5 \\
Religion & 9 & 57.6 \\
$\quad$ Muslim & 6 & 42,4 \\
$\quad$ Non-Muslim & & \\
Sex & 10 & 64.6 \\
$\quad$ Male & 5 & 35,4 \\
$\quad$ Female & & \\
Durations of treatments & 10 & 68.7 \\
$\quad<1$ years & 5 & 31,3 \\
$\quad>1$ years & & \\
\hline
\end{tabular}

This research resulted in seven themes, namely hallucination content, predisposition factor that causes hallucination, patients' response when hallucinating, the distress facing by the patients with hallucination, actions taken when hallucinating, the obstacles experienced by the patients, and their expectations.

\section{Theme 1. Hallucination content}

Based on the interview result, there are two sub-theme of the hallucination content. The first subtheme is the content of the hearing hallucination and the second is sight hallucination content. Based on the research result, it is concluded that the sight contents experienced by the participants are seeing shadows, people, moving objects, and the picture of skull. Meanwhile, the content of hearing hallucination is listening to a voice giving orders of what to do, whispers, ringtones, and unknown and unclear voices.

\section{Theme 2. Predisposition}

Based on the interview result of the predisposition factor, it is concluded that there are two sub-themes, namely biological cause and social cause.
The biological factor which makes the participants hallucinating is the side-effect of narcotics, psychotropic, and other addictive substances consumed by the participants. Meanwhile, the social factor is the lack of social interaction between the participants and their surroundings.

\section{Theme 3. Patient's subjective response when hallucinating}

Based on the interview of the patient's response when hallucinating, it is concluded that there are three sub-themes. They are pleasant subjective response, unpleasant subjective response, and no change on feelings. The unpleasant responses when hallucinating are the feelings of restlessness, confusion, panic, fright, anxiousness, anger, being fed up, unhappiness, hatred, distress, sadness, and puzzlement. Meanwhile, the pleasant subjective response is happiness. The participants also do not feel anything when hallucinating because that it has been a daily thing for them.

\section{Theme 4. Actions taken when hallucinating}

The research result shows two sub-themes of actions taken when hallucinating. The first sub-theme is the participants do nothing. The second is the participants commit an action to overcome the hallucination. Doing nothing toward the hallucination means being passive, sleeping, ignoring themselves, or locking themselves when the hallucination occurs. Meanwhile, the actions taken by them to overcome the hallucination are closing their ears, having a chat, scolding the hallucination, waking back and forth, being angry, wrecking furniture, doing what the hallucination commands to do, answering the hallucination, laughing, closing their eyes, taking medicine, doing spiritual activities, and doing outdoor activities and running.

\section{Theme 5. Encountered distress}

The research result signifies that the distress encountered by the participants is distracted mind, bothered surroundings/broken furniture, being unfocused, disturbed activities, headache, insomnia, difficult to eat, not being able to work, misbehaving, laziness, being inconvenient, an unable to get along with friends and disharmonious family.

\section{Theme 6. Obstacles experienced by the patients}

The research result brings out three sub-themes of the obstacles experienced by the participants. They are internal obstacles, obstacles coming from the hallucination itself, and external obstacles. Internal obstacles are the participants forget the actions taught 
by the nurses in controlling the hallucination, being lazy managing the hallucination, being unfocused doing anything, having nothing to do, being alone all the time, and not taking medicine. The obstacles coming from the hallucination itself are how strong the hallucination is and the hallucination duration. The external obstacles are friends who often bother noisy environment and stigma from surroundings.

\section{Discussion}

Hallucination is a false perception experienced by the patients which involves five senses, namely hearing, sight, groping, tasting, and smelling. The research result shows that the type of hallucination experienced by the patients is hearing hallucination and sight hallucination. This research result is in accordance with the previous theory stating that the type of hallucination which mostly takes place is hearing hallucination and sight hallucination [4].

The contents of hearing hallucination encountered by the participants in this research are commands, whispers, ring tones, baby cry, and unknown and unclear voices. According to Rogers et al. in Birchwood, the content of patient's hallucination is in the form of commands which commonly destructive to the patients and surroundings [5]. Cancro and Lehman in Videbeck state that it can be in the form of people chatting or talking about patients [7]. The voice can come from one person or many and can be in the form of either known or unknown voices. The hallucination contents are commands to do something, criticize a person, insult patients, threaten others, talk about other people, debate with other patients, please other patients, ask about something, and laugh other patients [5].

The content of sight hallucination experienced by the participants in this research is seeing shadows, people, and images. It can also be in the form of seeing shadows like some scary light [7]. Patients can also see the form of geometry, cartoon, or the mixture between complex image/shadow which is pleasant or scary [4].

Hallucination can be caused by biological, psychological and socio-cultural factor [4]. The biological factor causing the participants having hallucination in this research is the influence from narcotics, psychotropic, and other addictive substances. In line with Shives' statement that narcotics, psychotropic, and other addictive substances are one of the biological factors which can cause schizophrenia [8].

Meanwhile, socio-cultural factor causing the participants having hallucination is the lack of social interaction between patients and surroundings. Seaward's research result state that interpersonal factor can be in the form of ineffective communication, excessive addiction, or withdrawing from relationship and losing emotional control [7].

Patients' responses when hallucinating can be subjective, such as pleasant feeling, unpleasant one or no change on the feelings. Sauosa mentions that there are $48.32 \%$ patients feeling angry when hallucinating [9]. Stuart and Laraia, a person feeling ashamed with his or her sensory experience, withdraws themselves from other people [4].

The research result signifies that the distress encountered by the participants is distracted mind, bothered surroundings/broken furniture, being unfocused, disturbed activities, headache, insomnia, difficult to eat, not being able to work, misbehaving, laziness, being inconvenient, and unable to get along with friends and disharmonious family.

It is proven that hallucination can cause distress [5]. More than $75 \%$ patients with hearing hallucination encounter very deep distress which is caused by the content of the hallucination they hear [10].

Birchwood [5] state that the distress the patient feels is caused by how often the hallucination is and the hallucination duration. The distress the patients encounter is due to loud voices in the hallucination, the content of the hallucination, and also the patient's belief to the hallucination contents [5]. This causes fright/ anxiety even depression on patients with schizophrenia.

The research result signifies that the participants' actions when hallucination takes place are being silent, sleeping, ignoring himself/herself, or locking themselves when the hallucination occurs or trying to stop the hallucination by closing their ears, having a chat, scolding the hallucination, walking back and forth, being angry, wrecking furniture, doing what the hallucination commands to do, answering the hallucination, laughing, closing their eyes, taking medicine, doing spiritual activities, and doing outdoor activities and running.

The patient's laughing when hallucinating is caused by the delightful content of the hallucination. The first step of hallucination is the hallucination feels nice. The patient's behavior also can be moving lips without any sound coming out. Besides, patients tend to do physical activity which reflects the content of the hallucination [4].

Stuart and Laraia also affirm that on the last step, hallucination becomes a scary sensory experience if the patient does not follow orders as instructed in the content of the hallucination. This mostly becomes the reason of patients' doing destructive action which harms themselves, others and surroundings [4].

The research result showed the obstacles encountered by the participants when doing attempts to control hallucination. The obstacles are the participants forget the actions taught by the nurses in controlling the hallucination, being lazy managing the hallucination, being unfocused doing anything, having nothing to 
do, being alone all the time and not taking medicine, how strong the hallucination is, and the hallucination duration, friends who often bother, noisy environment, and stigma from surroundings.

Participants forget the actions taught by the nurses about how to control the hallucination. This happens because the application of how to control the hallucination should be based on knowledge and learning process. Notoatmodjo et al. [11] state that the changes on the behavior are similar with the learning process. Djamarah signifies that learning is the process of changing behavior by doing practices [12].

The patient's knowledge in controlling the hallucination is the basic matter in the process of behavior change. Without a strong knowledge basis, then the behavior shown will not last long. Knowledge is the result of knowing and it occurs after the person conducts sensory toward a certain object. Knowledge is a very important domain in shaping somebody's action [11].

\section{Conclusions}

This research resulted in six themes, namely hallucination content, predisposition factor that causes hallucination, patients' subjective response when hallucinating, the distress facing by the patients with hallucination, actions taken when hallucinating, and the obstacles experienced by the patients. Recommendations: It is a necessary intervention to decrease hallucination.

\section{Acknowledgments}

The authors would like to thank for the support of the Ministry of Research and Technology
Higher Education of the Republic of Indonesia, Prof. Dr. Runtung, SH, M.Hum as the Rector of University of Sumatera Utara.

\section{References}

1. Townsend CM. Essentials of Psychiatric Mental Health Nursing Philadelphia, PA: FA Davis Company; 2005.

2. McLeod T, Morris M, Birchwood M, Dovey A. Cognitive behavioural therapy group work with voice hearers. Part 1 . $\mathrm{Br} J$ Nurs. 2007;16(4):248-52. https://doi.org/10.12968/ bjon.2007.16.4.22995

PMid:17363859

3. Coupland K, Macdougall V, Davis E. With One Voice: Guidelines for Hearing Voices Groups in Clinical Setting, United Kingdom; 2010.

4. Stuart GW, Laraia MT. Principle and Practice of Psychiatric Nursing. $8^{\text {th }}$ ed. Philadelphia, PA, USA: Mosby, In; 2005.

5. Birchwood. Cognitive Behaviour Therapy for Command Hallucination; 2009. Available from: http://www.publications. cpa. [Last accessed on 2010 Dec 21].

6. Birchwood. Cognitive Therapy for Command Hallucinations: Randomized Controlled Trial; 2004. Available from: http://www. schizophrenia.com. [Last accessed on 2010 Jan 29].

7. Videbeck SL. Textbook of Mental Health Nursing. Jakarta: EGC 2008.

8. Shives LR. Basic Concepts of Psychiatric-Mental Health Nursing. Philadelphia, Pennsylvania: Lippincott William Wilkins; 2005.

9. Sauosa. Types and Contents of Hallucinations in Schizophrenia; 2007. Available from: http://www.jpps.com.pk/ display_articles.asp?d=164\&p=art; 2007. [Last accessed on 2010 Jan 28].

10. Wong. Experience and Coping with Auditory Hallucinations in First Episode Psychosis: Relationship with Stress Coping; 2008. Available from: http://www.psychservices.psychiatryonline. [Last accessed on 2010 Jan 19].

11. Notoatmodjo S. Health Promotion and Behavioral Sciences. Jakarta: PT. Rineka Cipta; 2007.

12. Djamarah SB. The Psychology of Learning. Jakarta: Rineka Cipta; 2008. 